\title{
Perspectives of Continuing Professional Development (CPD) for Kenyan Midwives
}

\author{
Lucy Gitonga, Njogu Samson Muriuki \\ Chuka University, Chuka, Kenya \\ Email: gitonga30@yahoo.com, njoguumuriuki2@gmail.com
}

Received 14 April 2014; revised 14 May 2014; accepted 22 May 2014

Copyright (C) 2014 by authors and Scientific Research Publishing Inc.

This work is licensed under the Creative Commons Attribution International License (CC BY). http://creativecommons.org/licenses/by/4.0/

(c) (7) Open Access

\begin{abstract}
Continuing Professional Development (CPD) provides an important strategy for reduction of maternal morbidity and mortality with the aim of attaining Millennium Development goals (MDG) four and five. However, there is a lack of information about how Kenyan midwives understand and perceive CPD and how this is situated in the practice and social context. This research aimed to explore Kenyan midwives' experience and perceptions of CPD. A descriptive explorative approach gathered focus group discussion and questionnaire data on beliefs, opinions, and perceptions, demotivating and motivating factors to CPD of a total of 25 midwives in a level five hospital in Kenya. Questionnaires were piloted and self-administered after cleaning and focus groups taped and transcribed verbatim. Data were analyzed thematically using inductive approach with the aid of SPSS computer program. Results: Four key themes emerged from the data: Midwives' views of CPD, their motivators for undertaking CPD, the choices they made around CPD, their demotivators for undertaking CPD. Congruence with the issues evident in the literature were: the difficulties with role diversity, the importance of CPD in personal and professional growth, the importance of flexible modes of study and the importance of a supportive culture for ongoing learning. The study findings helped in identifying gaps in the literature about Kenyan midwives' perspectives on CPD.
\end{abstract}

\section{Keywords}

Continuing Professional Development, Motivators, Demotivators, Maternity

\section{Introduction}

Descriptive exploratory study was carried out in a level 5 hospital in Kenya on perspective of Kenyan midwives on CPD. The attainment of Millennium Development Goal (MDG) 4 and 5 requires adequate national researchers of skilled birth attendants [1]. Nurses, midwives and their equivalents form the front line of the formal health 
system and a critical element of global efforts to reduce morbidity and poverty in developing countries. Political will and support is crucial both nationally and internationally. The reduction of maternal death rates (50 to 400 times higher in low-income than industrialized countries) is an urgent political and ethical call for action. Skilled birth attendants are the key to reducing maternal and neonatal mortality. Therefore, planning and management of nurses and midwives is needed to reach 73\% coverage by 2015 [1].

The idea that health professionals should be accountable to the society they serve is not a new concept and for a long time as stated by Fleet (2008), that is, as early as the beginning of the $19^{\text {th }}$ century, the continuing professional development (CPD) of health professionals has been seen as one way in which a population's level of health could be improved. The public was, and is still today, increasingly demanding a system that is more responsive to regional and community needs. As a result, there is a need for more health professional education at all stages of the education continuum — undergraduate, postgraduate, and continuing professional developmentthat meets the health and social needs of the populations being served. The trend is now towards "socially accountable" health care, meaning that the broader context of CPD must also include the personal, social, and political aspects of health care and as such, involve a widening of accountability to patients, the community, managers and policymakers [2]. CPD planning must take into account local and national priorities as well as personal learning needs. Flexible modes of study and venue for undertaking CPD as stated by [2] [3] must be adopted to allow midwives to participate in CPD activities without necessarily removing them from the area of practice in order to address the severe shortage of staff. There is plethora of activity both globally and locally geared towards addressing maternal and neonatal morbidity and mortality [3]. This has placed the role of midwives in sharp focus as governments think of ways of ameliorating this problem. Since the number of midwives in subSaharan Africa and Kenya in particular, is limited, innovative ways of improving their knowledge and skills in highly effective targeted obstetric and newborn interventions without removing them from the workplace are desirable [4]. Midwives offer evidence-based, cost-effective high impact care [4]-[6]. Moreover as competent care providers, midwives detect problems early in complicated births, take appropriate life-saving actions immediately and refer where appropriate. Additionally, their critical thinking and decision make skills contribute to the saving of lives by making timely decisions and action taking [6]. In this regard therefore, there is need to strengthen their skills through continuing professional development (CPD). Anecdotal evidence suggest that increasing demands on service delivery have reduced time available for CPD activities in many countries coupled with less support from service providers in relation to staff needs [7].

In line with government initiatives, this study was intended to establish perceptions of CPD activities, motivating and inhibiting factors of CPD among midwives in maternity units in Kenya with the ultimate aim of making recommendations for strengthening CPD practice among midwives which will consequently enhance quality of care provision within these set ups.

Continuing Professional Development refers to a specific form of continuing education that helps those in any field maintain competence and learn about new and developing areas in their field. It is an essential aspect of post-registration education and practice which has been seen by many researchers as central in self-regulating disciplines like nursing [8]. The importance of CPD for nurses and midwives has been getting greater emphasis in the past few years. [9] defines CPD as:

"A lifelong process, which includes both structured and informal activities and which may include formal educational programmes". Lifelong learning is a well established concept and there has been a growing attention all over the world to developing a positive attitude towards learning throughout life [10]. "It is any planned series of incidents at any time in the life span, having a humanistic basis directed towards the participants learning and understanding” [11]. Approximately 6.3 million perinatal deaths and 500,000 maternal deaths occur annually all over the world with 99\% occurring in the developing countries and are avoidable [12]. According to World Health Organization [12], most of the interventions aiming at reducing perinatal and maternal mortalities need a responsive health system. A responsive health system is one offering appropriate antenatal care; comprehensive emergency obstetrics care and quality delivery services. A crucial question in the aim of attainment of MDG 4 and 5 is whether it can be attained faster with the scaling up of multipurpose health workers operating in the community or with the scaling up of professional skilled birth attendants working in the health facilities according to [13]. This question is worthy being answered because as indicated in National Road Map-Kenya (2010), despite the high impact strategy of reducing maternal mortality, maternal and neonatal morbidity and mortality levels continue to be recognized internationally as public health priorities. Moreover these indicators in Africa have continued to rise instead of declining since the launch of Safe Motherhood Initiative 15 years ago. 
Of all maternal deaths occurring globally, 99\% of them occur in developing countries with Sub-Saharan Africa having the highest maternal mortality ratio of 900 maternal deaths per 100,000 live births and also the highest life time risk of maternal death of 1:26. Despite recent developments, health care in Kenya remains suboptimal. Difficult terrain, economic crisis, endemic diseases and high population numbers coupled with limited availability of qualified and competent health care professionals all contribute to poor health status particularly maternal health. In a country with a population of approximately 38 million (Kenya Demographic Health Survey (KDHs) 2008/2009), there are currently an estimated 54 nurses/100,000 population. Maternal mortalities in Kenya have remained increasing since 1998 to 488 maternal deaths per 100,000 live births in the year 2008/2009 (with some regions reporting maternal mortalities of over 1000/100,000 live births). Neonatal mortality rate has recorded a marginal reduction from 33\% in 2003 to 31\% in 2008/2009 compared to other indicators of child survival. Although evidence is scarce on what it takes to progress on this path especially at such a time when we have reached the twentieth anniversary of the save motherhood initiative with minimal progress made [14] [15] state that the need to invest in training of midwifery workforce and ensuring that midwifery providers have the appropriate life-saving skills have been topics of discussion for decades yet the majority of women deliver at homes. The WHO definition of skilled birth attendant states that a skilled birth attendant is an accredited health professional such as midwife, doctor or nurse who has been educated and trained to proficiency in the skills needed to manage normal pregnancies, child birth and the immediate postnatal period and in the identification, management and referral of complications in women and newborns.

In Kenya although every civil servant is supposed to cover 20 CPD hours in a year there are no guidelines on how and where to cover them. More specifically, although hospitals in Kenya have CPD programmes which are mainly irregular (no clear framework), majority of the hospitals do not have programmes for nurses specifically and for midwives for that reason. Additionally, in Kenya continuing professional development activities, needs driven should be done before coming up with the program. Additionally, selection criteria for nurses doing specialized courses have been set so that the nurses/midwives who are interested in the area are willing to share knowledge qualifies. More so the Ministry of Health [16] [17] in Kenya has developed the following strategies in order to ensure that all staff participates in Continuous Medical Educations: post basic scholarship, scholarships for short courses, specialized workshops, Continuous Medical Education at stations, conferences, on-job training budgetary provision made at departmental levels and giving its staff paid study leaves. To emphasize this, the Ministry of Health's (Kenya) future plans, include: Continuous Medical Education should be the basis for promotion and create more Continuous Medical Education opportunities. Evidence has shown that there is need to change from the traditional methods of teaching of paper and pen to evidence-based practice by orienting providers to new strategies which were not initially included in the basic curricula [18]. In Kenya the government's support for nurses to advance in several courses and midwifery is not among them. Additionally, the only School of midwifery that exists in Kenya training midwives at post registration level admits a maximum of five students per year who are self sponsored. This is too costly to maintain as a college. This necessitates the need to analyze the dynamics of CPD practice in Midwifery in Kenya.

\section{Methodology}

This was a descriptive exploratory study [19] utilizing an interviewer-administered questionnaire since little was known about the study area in Kenya, that is, situation of midwives' practice of CPD in Kenya. This kind of study design was chosen because the main aim was to describe the phenomena in as much details as possible in terms of how they are. Moreover an exploratory design [19] was chosen because it was studying an area that was not known hence attempting to identify new knowledge, new insights, new understanding and new meanings. Moreover [20] support this by stating that descriptive designs are particularly useful when little is known about a certain phenomenon and that they are a way to start building up knowledge about a topic and are used to conduct an initial exploration on a research question The results of this study were not really to make generalization to the larger population but provide a better understanding of the population being examined, with the aim of making recommendations for a further research to identify the relationship between the midwives perspectives of CPD and the factors identified. Additionally, exploratory studies are more flexible and they allow the study to occur in a natural setting [20]. Moreover as [21] state, flexibility in exploratory research design is best suited for studies of this type in that it allows the researcher to change direction as the knowledge of the variables increases. This is because ideas occur as data is collected and examined hence one would be guided by 
the emerging issues. Additionally, [22] states that a descriptive study tells us how many (what proportion of) members of a population have a certain opinion or characteristic or how often certain events occur together (that is, are associated with each other); they are not designed to explain anything or to show casual relationships between one variable and another. This is because the research was only to tell how many midwives have been practising CPD by age, qualification, among other variables but she was not able to tell the relationship between this and the actual practice. The data collected was essentially fact-finding and descriptive and also used to make predictions and recommendations for analytic design to answer the "why" questions. Wood and Ross (2006) support this by stating that the design is descriptive because it was describing a phenomenon and a lot of information could be acquired through description. An in-depth exploration and description was required to inform of the current practice of CPD, motivating factors and demotivating factors to CPD participation by nurses. However as [22] states, descriptive designs cannot be used to determine the amount of differences between groups, relationships of characteristics or causality. Although this research was intended to reveal the current practice, motivating factors and demotivating factors of CPD by Kenyan midwives, it was not able to tell why the differences in terms of the demographic factors for example and that is why further research is necessary.

Target population was all nurse midwives, both registered and certificate (enrolled) working in the maternity units of Kenya and the accessible population was all midwives working in the maternity unit of the above hospital_who were on duty during the study period (2 weeks). There were Thirty six (36) nurses in total. According to the Kenyan duty Schedules, by the end of the two weeks all the midwives were on duty at a certain time. This meant that the thirty six were the sample size. Response rate of at least $66 \%$ as supported by Taylor et al. (2007)\% and above was to be representative. Convenience sampling was used and all nurses on duty during the study period were given the questionnaires. A convenience sample as defined by Ross and Wood (2006) is a non probability sample that happens to be available at the time of data collection. Convenience sampling is whereby the research subjects are picked as they are until the researcher gets the number that he or she had intended to achieve as supported by [22]. Convenience sampling is used when; a minimum number of subjects (or time frame) is determined in advance, every person who meets the criteria is asked to participate, the researcher goes to setting and selects sample from persons meeting the sample and the actual population is not known. They are inexpensive, less time consuming and provide means to conduct studies on topics that could not be examined with probability.

Data was collected by use of a questionnaire and focus group discussion. Focus group was used to obtain in-depth information on concepts, perceptions and motivating and demotivating factors from the group. The responses were recorded on a paper and then the facilitator read the responses as they were for the group to collate and prioritize ideas in order to remove duplications, "off the wall remarks" or responses that were judged by the group to be of minimal help or relevance to the research question/aim or context [22]. The report was analyzed by the researcher through content analysis. The main themes to be explored were demographic data, perceptions of CPD, motivating factors and hindrances to CPD practice with the aim of answering the research questions.

To increase response rate, a descriptive title for the questionnaire was written as well as introductory letter.

Since this was a level one (whereby the knowledge about the research topic is limited because little or no research has been done, therefore little or no literature is available hence to answer the research question an exploration of the topic in great depth and detail is required) study, it involved two main steps. That is content analysis and frequency tabulations. Data was cleaned to eliminate some of the more obvious errors that may have crept in during the preceding stages (frequency distributions, range-checks and internal consistency) as stated by [22] and analyzed both qualitatively and quantitatively. Qualitative data was analyzed by content analysis of the themes that emerged where as descriptive statistics and inferential statistics were used to analyze quantitative data. Qualitative data was analyzed by descriptive statistics. After data collection, coding was done and then entered into a data sheet on SPSS. Coding was according to the three main themes and any other emerging theme: CPD activities, motivating and inhibiting factors. Description of the distribution and range of responses to each variable was done and data examined for skewness. Data was categorized on a nominal scale, defining them carefully so as to ensure that they were mutually exclusive. A descriptive summary of the data was then made. Frequency distributions in terms of graphs, charts and tables was then used as well as measures of central tendency such as mean, median, mode and range and standard deviation to show the dispersion of data. Tests of association (Chi-square) was to be used to enhance the answer to the question but was not found neces- 
sary during analysis.

\section{Results}

\subsection{Area of Practice}

The research was carried out in a maternity unit of a level five hospital in Kenya which comprised of Antenatal ward, Labour ward, Newborn Unit (Nursery) and Post natal ward respectively.

According to the results, the staff deployed at the Antenatal ward participated in CPD 100\% while those in postnatal ward had the least attendance. The practice of CPD here is not influenced by the workload or area of deployment as seen in the literature [3] [4] [6] but according to the results, all those that did not participate in CPD cited the lack of being given a chance as the only reason as to why they did not participate. However it is necessary to explore the attitude towards managers on the importance of CPD in improving quality of patients care since everybody should be given a chance to practice.

"I really want to have a chance to participate in developing myself professionally. This will keep me updated and enable me to care for my patients better but I have never been given a chance. I am ever left to cover shortage.” (Participant-FGD).

\subsection{Qualification}

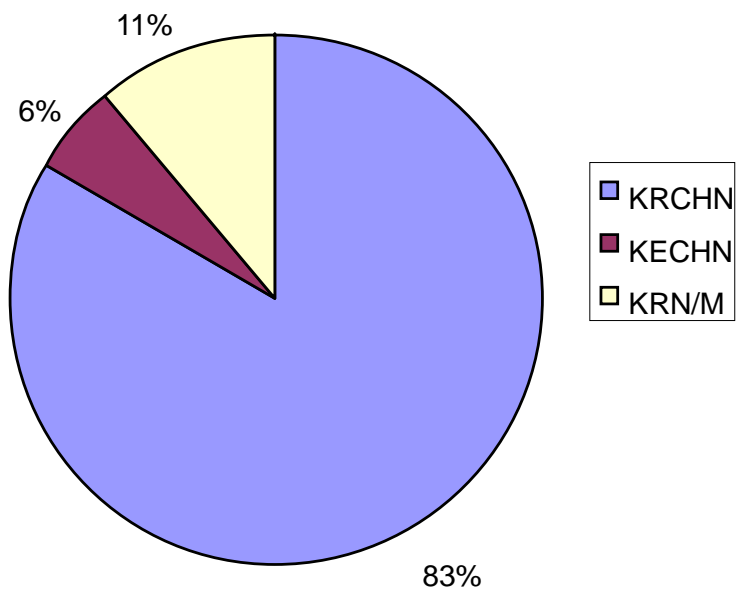

The results indicate that the midwives are willing to participate in CPD regardless of their qualification but some are not given a chance. Moreover as [7] [8] found out that in some instances managers are the ones who decide who attends CPD, this could be so for this research because all those who did not attend failed to do so because they were not given a chance. However, the results do not agree with [9] [10] who stated that junior staff feared to participate in CPD because they would face obstacles from their seniors in terms of implementation. This is because according to the results, all the enrolled midwives had participated in CPD as opposed to the registered midwives.

“...but sometimes you have no choice since it is the in charge who decides who to attend" (participant FGD).

\subsection{Duration of Practice}

According to the findings, the longer one had served in the profession the more the chances of engaging with CPD. This could be supported by the findings from the literature that managers had an influence in deciding on whom to attend. That is to mean that the longer one had stayed in the facility the more likelihood that he or she is known to the in-charge therefore qualifying to be offered a chance more easily to practice CPD.

\subsection{Gender}

$92 \%$ of the samples were females whereas only $8 \%$ were males. This could be probably associated to the factor 
that nursing has been dominated by females up to date. All the males had had CPD within the last six months as opposed to females. This could be due to the fact that women hold collective responsibilities which were cited by [11] to include both social and work related responsibilities as opposed to men. When asked about factors hindering them from participating in CPD during Focus Group discussion (FGD), one responded; "Sometimes the work at home is too much. I have children to take care of..., therefore having time to go to school is a real challenge.” (Female participant-FGD).

\subsection{Shift Pattern}

Evening shift means working from $7.30 \mathrm{am}$ to $5.00 \mathrm{pm}$ while Half day means working from 7.30 am to $1.00 \mathrm{pm}$.

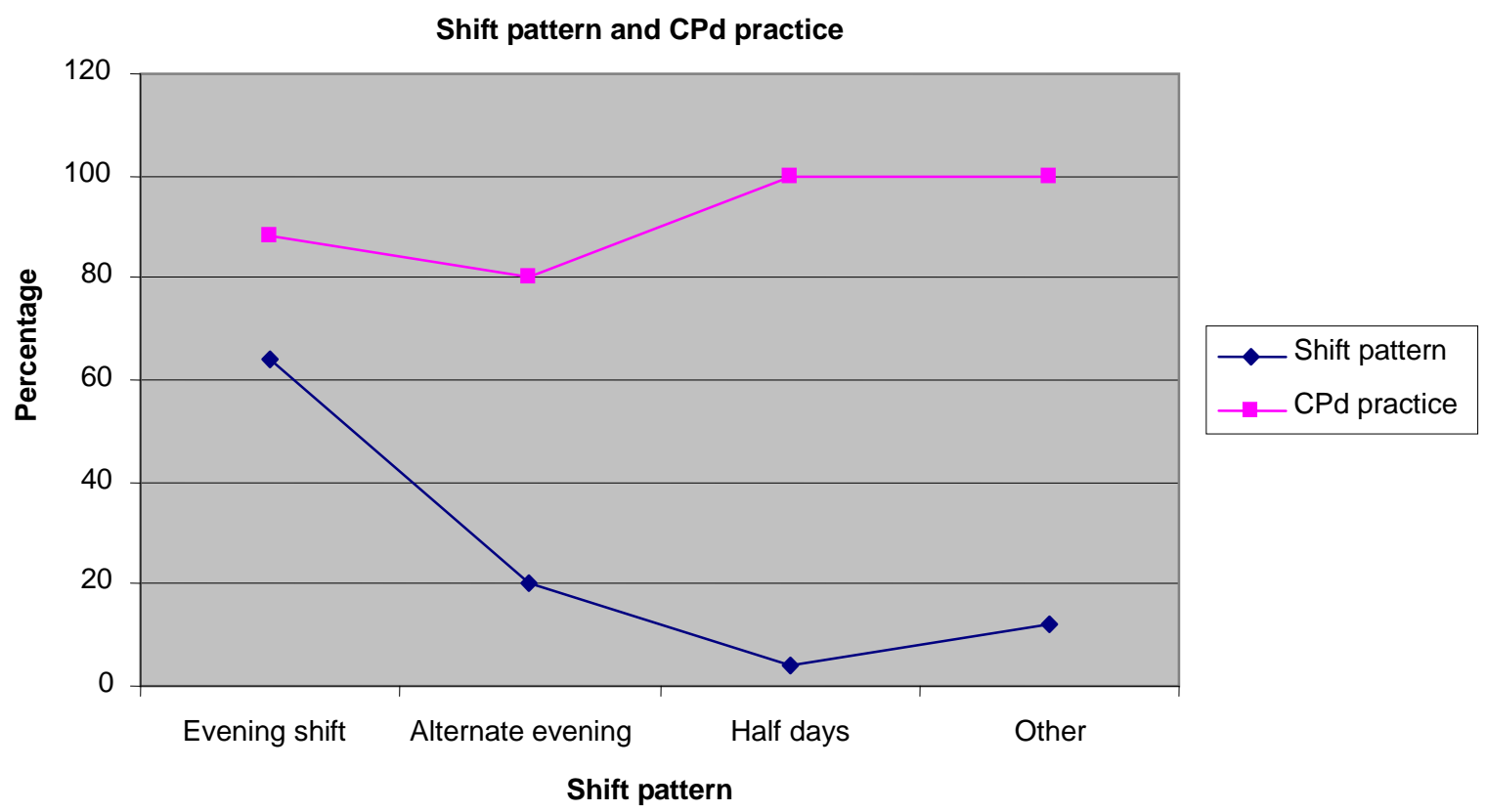

The results indicate that those on half day duty and other (to include night duty) practised CPD more. This could imply that they had more time for CPD as lack of time was cited in the literature as one of the factors hindering staff from practising CPD.

"Sometimes I am on duty all day long and I have no time for attending any form of training. The available schools offering evening classes are too far for me to attend.” (FGD Participant).

[12] supported this by stating that lack of time, distance from classes and reluctance to walk out at night were cited as some of the factors hindering health workers from attending CPD.

"The ministry should think of how to make education available to some of us who are not able to walk far to attend classes. Surely we are not happy...” (FGD participant).

\subsection{Opinion towards CPD}

All the midwives interviewed stated that CPD was useful (100\%). This supported by [13] who in their research found out that nurses have curiosity to learn and know more about anything related to their work hence must be involved in any activities that would improve their work. This also justifies why the majority agreed that CPD activities are useful for personal development among other reasons including those who had not practised for the last six months.

\subsection{Participation in CPD}

Eighteen participants [18] who are equal to $72 \%$ practised CPD while six [6] that is $24 \%$ did not. Only one (4\%) left the questionnaire blank. All the $24 \%$ who did not practise CPD cited lack of chance as the main reason as to why they did not practise but during FGD, availability of schools (distance) and lack of time were also cited. 
The results of the duration of CPD for those who practised CPD are as below.

\subsection{Participation in CPD}

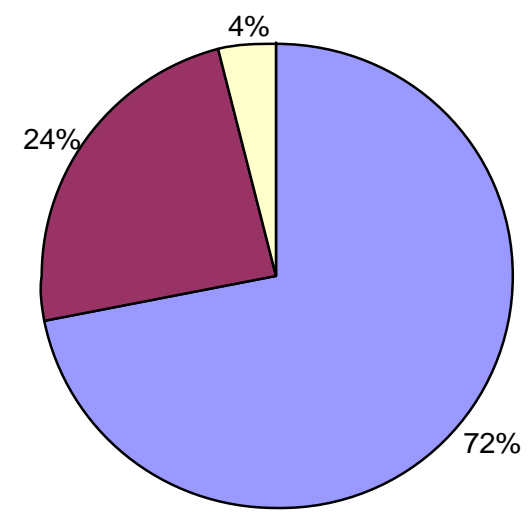

$\square$ Participation in CPD
$\square$ Non participation
$\square$ Unknown

"I would imagine a situation where one day all the courses will be available at our medical training college here allowing flexibility in study. I will be the first to enroll.” (FGD participant).

\section{Duration of CPD practice}
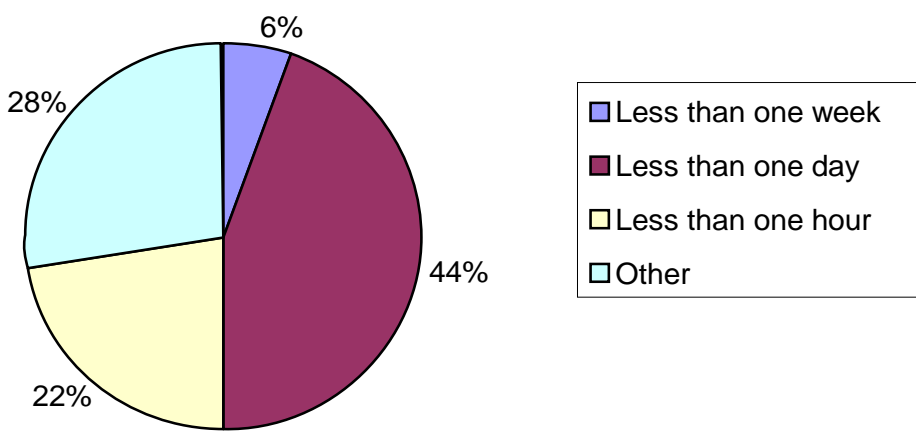

According to the results majority of the midwives have had a CPD activity which lasted for less than a day? This could be associated to the factors that were cited earlier, that is lack of time to attend longer courses and the decision being made by managers on who to attend what and the duration. Additionally the ministry has set a policy to control the number of staff attending CPD activities on full time basis and that one must work for at least two years after completing a course that lasts for six months and above before attending another course lasting for six months and above. The same case applies to new employees. This could be a reason for those who had worked for less than one year not attending any CPD activity. Probably because they had not completed the two years in practice or may be they did not prefer shorter CPD activities. A further research can be done to probe further by asking the ones who did not attend and had worked for less than one year why they did not attend.

"Most of the time we are just called upon to attend a CPD within the hospital and we can not really have control over the duration or the content. We just have to attend" (FGD participant).

\subsection{Involvement in CPD Planning}

When asked whether they were involved in planning for their CPD activities 22 (88\%) said No, 1 (4\%) said yes, 1 (4\%) said sometimes while 1 (4\%) did not answer this question. This could explain why majority of those who practised CPD did it for less than a day where as the safe motherhood courses last for a minimum of three days and above. [14] cited lack of individual involvement in planning as one of the factors hindering staff to practise CPD. Additionally the Ministry of health dictates that needs assessment must be done in the facilities to ensure that the needs of staff and patients are addressed. 


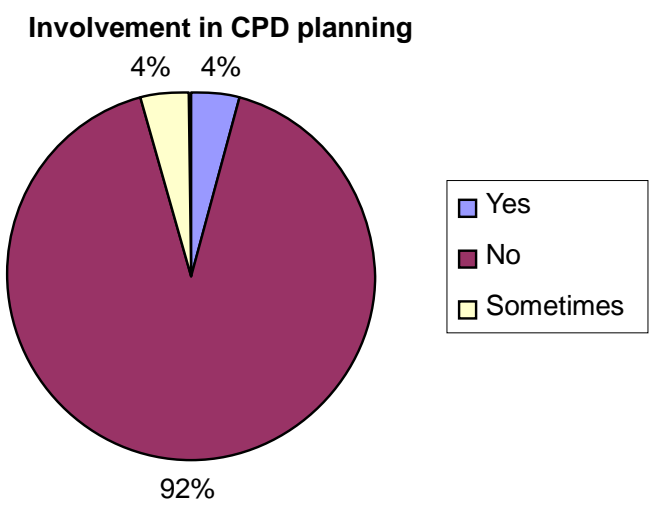

\subsection{Preferred Place for CPD and Mode of Study}

[15] requires that innovative ways of improving midwives' knowledge and skills in highly effective targeted obstetrics and newborn interventions without removing them from the place of work. This necessitates development and adoption of various modes of study to ensure that staff can practise CPD without necessarily having to go away from place of work and this will help to address the staff shortage that exists globally. When asked to state the place and mode of study they would prefer, $48 \%$ of the participants preferred to be away from the place of work, $40 \%$ of them preferred to have CPD activities at the place of work while $12 \%$ of the participants preferred other modes like reading journals, internet among others.

"I do not have to go to a class and learn. Nowadays there is even internet which can give you all the information that you need." (FGD participant).

"We do not need to go to class to learn. The hospital should ensure that there is a resource centre which has up to date resource materials for staff to read during breaks.” (FGD participant).

Out of those who preferred to be away from place of work, $40 \%$ preferred part-time mode while $60 \%$ preferred full time. All those who preferred to have their CPD activities at the place of work preferred part time as the best mode of study. Overall, $60 \%$ of all the participants preferred part-time as the best mode of study. "I would like a situation where I can walk to a class for two hours and come back to work without necessarily having to go away for a very long time.” (FGD participant).

"I don't think I should be away from work so that I can learn..." (FGD participant).

"I can not concentrate in class as well as I am on duty and again taking care of my family. I would prefer going to a dormitory and sleep there. There I can concentrate more” (Participant-FGD).

\subsection{Midwives Views towards CPD}

When asked about how they rate what motivates them to undertake CPD, 12 participants (48\%) strongly agreed that they are self-motivated, 12 (48\%) agreed while only 1 (4\%) disagreed. This is to say that 24 (96\%) participants are self-motivated to do CPD if given a chance. This is also supported in the literature by [16] [17] who states that nurses have the curiosity to learn given a chance therefore managers should give equal chances to all for CPD practice.

When asked to rate their views on the ability of CPD activities to enable personal development, 14 (56\%) participants strongly agreed while $11(44 \%)$ participants agreed. This is to say that all the participants' value CPD for personal development. This is supported in the literature by (16) in a study on nurses' attitude towards CPD in UK who found out that nurse felt that CPD made them become self-directed, critical and reflective practitioners.

At the same time the midwives had similar opinion when they were asked to value their perception towards the role of CPD in midwifery development. Here was a 100\% response that they all agreed that it is useful.

When asked to rate their opinions towards the use of CPD activities in improving quality of patients care, 17 (68\%) participants strongly agreed while 7 (32\%) participants agreed respectively. This means that there was $100 \%$ agreement that CPD activities were useful in provision of improved quality services to patients.

On their opinion towards the usefulness of CPD activities towards developing leadership skills, 12 (48\%) participants strongly agreed, 12 (48\%) participants agreed while only 1 (4\%) disagreed. This implied that nurses 
felt that being prepared for leadership and management positions could empower them to become more empowered in executing their duties. This if explored further can be a good justification to why ward and hospital in charges should undergo leadership course before taking up managerial positions. Additionally it can be used to support the Kenyan Government policy of September 2010 which requires all government officers to have undergone a leadership and management course before being promoted to job group " $\mathrm{M}$ " and above. Whereby these officers are accounting officers of the Governments. According to the Government of Kenya scheme of service for civil servants.

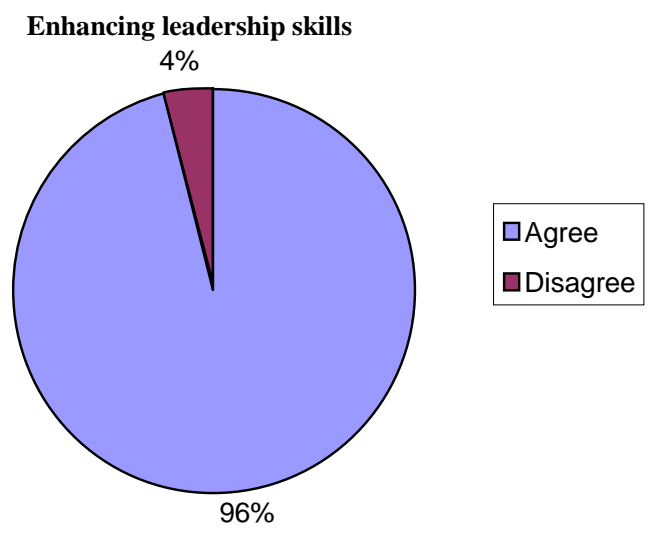

Moreover, when asked about their views about whether they have time for CPD activities, 6 (24\%) participants strongly agreed, 4 (16\%) participants agreed, 8 (32\%) participants disagreed, 4 (14\%) strongly disagreed, 2 (8\%) participant said it was not applicable while 1 (4\%) participant left it blank. This was to say that $40 \%$ of the participants agreed that lack of time was the main demotivating factor. $46 \%$ of the participants disagreed with the fact that lack of time was a factor hindering their CPD practice and this could be associated with lack of chance as was cited in the previous questions. As stated in the literature by [16], lack of time was cited in many researches as one of the hindrances to staff participation to CPD hence this should be put into consideration when planning for CPD activities for staff. Again the results have also revealed that those who are doing straight day duties practise CPD less than those doing night duty and half days hence qualifying lack of time as a factor demotivating nurses to practise CPD.

On the usefulness of CPD towards ones promotion, 7 (28\%) participants strongly agreed, 6 (24\%) participants agreed, 3 (12\%) participants disagreed, and 1 (4\%) participant strongly disagreed while 8 (32\%) participants did not answer. Overall 52\% of the participants (majority) agreed that CPD is important for their promotion. The issue of cost was cited in the literature by [16] [17]. When the midwives were asked to give their views on the fact that CPD activities are expensive and time consuming, 4 (16\%) participants strongly agreed, 1 (4\%) participant agreed, 12 (48\%) participants disagreed, and 7 (28\%) participants strongly disagreed while 1 (4\%) participant said that it was not applicable. This is to say that overall, 20\% agreed that CPD activities are time consuming and expensive while $76 \%$ disagreed. Although literature cites cost [18] as one of the hindering factors to CPD practice that were mentioned (staff not able to attend continuing professional development due to lack of funds), the results reveal that midwives are self motivated to learn and the issue of cost is not the main demotivator. The results can justify why it is not a must that money should be available at the facilities in order for them to conduct CPD activities for staff. However the results do not reveal whether the issue of cost is to do with long courses or short ones although according to the results majority of midwives who had undertaken any CPD activity within the last six months had done CPD activities which had lasted a day or less.

When asked about their views on the CPD activities being dictated by the service needs of the hospital, 7 (28\%) participants strongly agreed, 5 (20\%) participants agreed, 9 (36\%) disagreed, 4 (16\%) participants strongly disagreed while one said that it was not applicable. Overall $48 \%$ of the participants agreed with the fact that their CPD activities are dictated by the service needs of the organization while $52 \%$ of the participants disagreed with this. This is to say that since the results have indicated that majority of the participants stated that they are self motivated to participate in CPD, then staff must be involved in planning for their CPD activities and that just as Fleet (2008) stated in the literature personal, social and political aspects of health care delivery must be put into 
consideration when planning for CPD activities in any organinization. This can be used by the MOH as a justification when they are emphasizing on the need to do need assessment of staff and organization for CPD activities in all hospitals and that every staff should be given an equal opportunity to practice.

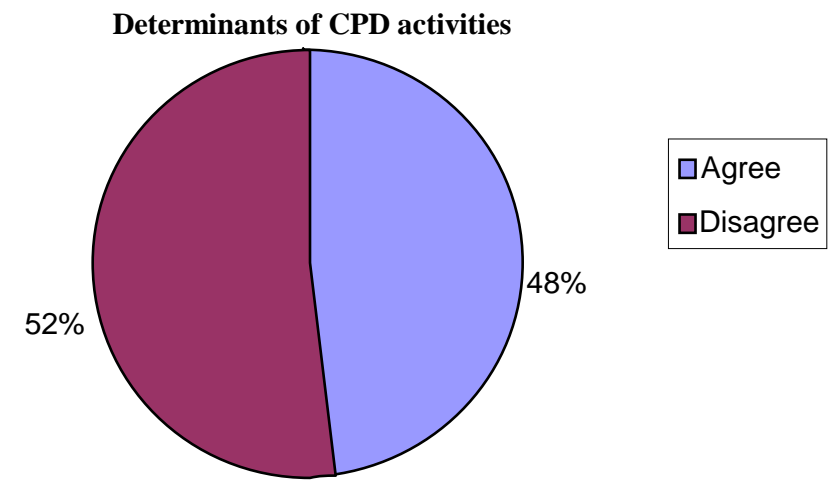

Although [19] found out that although there was need to integrate CPD opportunities in the continuous professional development program, clear strategies of how to achieve this was lacking, the results indicate that there were well defined structure of CPD activities in the hospital. This was revealed in the answer to a question whereby the midwives were asked to give their opinion on the fact that there was no clear structure of CPD activities in the facility.

\subsection{Courses Attended}

The participants were asked to list the causes they had attended after their basic registration. This was to relate the relevance of the causes attended and their area of practice and the main aim of contributing towards reduction of MDG 4 and 5. The main causes that were listed by the participants were classified into four main categories as illustrated by the chart below:

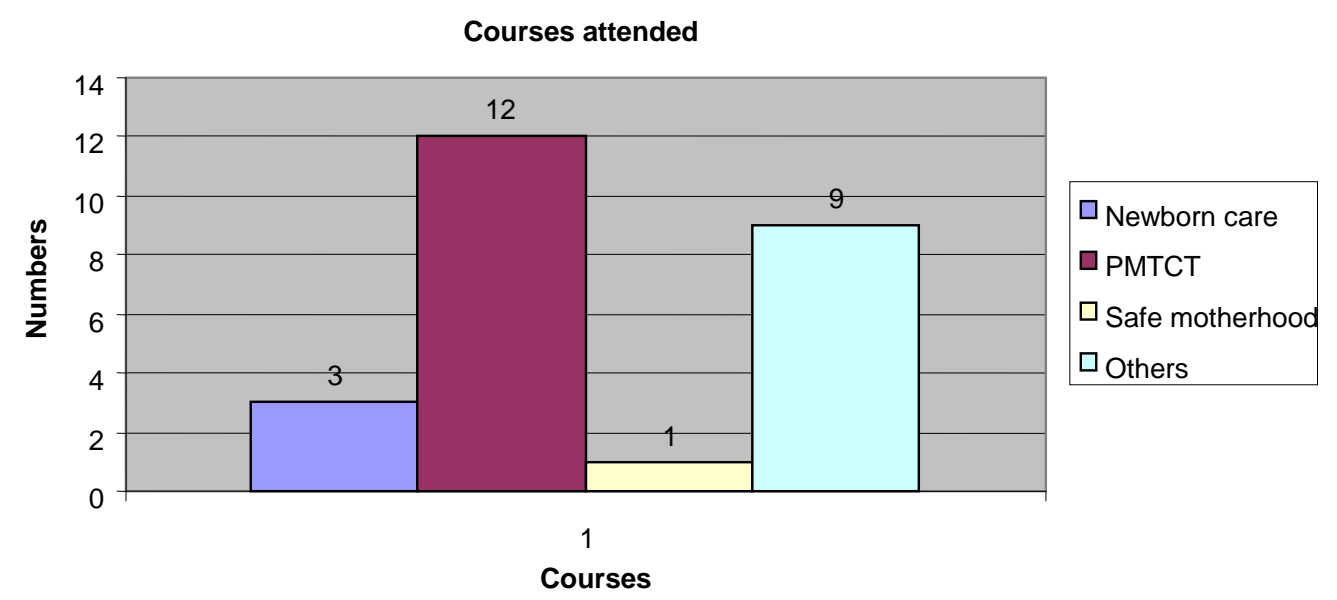

Although [20] advocates that midwives' knowledge and skills should be enhanced in highly effective targeted obstetrics and newborn interventions, the results reveal that majority of the participant have done courses that are not directly related to the first five major causes of morbidity and mortality in both mothers and newborn. The main causes of mortality for mothers as seen in the reviewed literature include; hemorrhage, sepsis, obstructed labour, hypertensive diseases and unsafe abortion while the leading causes of neonatal deaths include sepsis, prematurity, birth asphyxia and congenital abnormalities. All the participants agreed that CPD activities are useful for their personal development and majority of them agreed that CPD activities are important for promotion. Therefore some nurses could be grasping any opportunity that they come across regardless of whether it was relevant to the area of practice or not. 


\subsection{Motivators to CPD}

When asked to list the things that made them to practice CPD, 10 (40\%) participants listed improvement of service delivery, 12 (48\%) listed personal development, 1 (4\%) participant listed promotion purposes while 2 (8\%) participants were classified as other.

"I was an enrolled nurse and I felt that I really had to upgrade to diploma so that I can be at per with the rest. You have no choice other than going to school so that you can be promoted. Again the ministry ha limited mobility for diploma and degree holders. Therefore I have to struggle and learn” (FGD participant).

"One has no choice. The nursing council requires that we attain some hours per year for us to be retained to practice. If one wishes to go and practice outside the country the council can not clear you unless you have a retention license to practice" (FGP participant).

\section{Discussion}

It was evident from the results that midwives were positive about CPD as all the participants stated that CPD was useful mainly for their personal development and improving service delivery to patients. This is also supported by [15] who stated that nurses stated that the knowledge gained through CPD was critical for professional development and growth. This could imply that strategies should be developed to offer equal opportunity for midwives to practice CPD so that they can be motivated personally. Others mentioned included retention in the council's register. This can be used to inform policy in that staff should be given a chance to undertake CPD since the knowledge gained will be used to improve service delivery. [20] supports the results by stating that skilled attendants' practice must be regaled to ensure that their skills and knowledge are regulated.

The main motivators to CPD as revealed in the results were personal development and service delivery improvement although the need for promotion and professional development were also mentioned. What was evident in the results also was the fact that most CPD activities were taken voluntarily without considering needs of the particular area of deployment. Lack of a formalized structure for topic selection was evident and this led to limited or repetitive selection of topics hence necessitating practice of courses that were not congruent with the needs of the specific area of practice which were clearly outlined by [21]. Data from this study suggest that midwives selected CPD topics that met individual needs and the needs of the job but planning was an overlooked aspect of CPD. Midwives were not involved in planning for their CPD activities. Those midwives working for straight day duties lacked time to practice CPD compared to the rest. Lack of time was cited by [22] as one of the major hindrances of midwives towards CPD participation.

Overall $60 \%$ of the participants preferred part-time mode of study while majority preferred to study within their area of practice. From the results, conclusions can be drawn that flexibility in designing the mode of study and the place of work is necessary when planning for CPD activities as supported by [22] who stated that there is need to develop more flexible courses targeted to actual rather than idealize learning needs of each nurse and allow more flexibility in their practice.

\section{References}

[1] Allen, D. and Hudges, D. (2002) Nursing and the Division of Labor in Health Care. Palgrave, Great Britain.

[2] AMREF (2003) Consultative Meeting on Continuing Medical Education and the Role of Information and Communication Technologies in Kenya. http://www.health.comms.org/pdf/cmi-icts_kenya

[3] Courtis, L. and Netten, A. (2002) The Costs of Training Nurse Practitioners in Primary Care: The Importance of Allowing for the Cost of Education and Training When Making Decisions about Changing Professional Mix. Journal of Nursing Management, 15, 449-459. http://dx.doi.org/10.1111/j.1365-2834.2007.00668.x

[4] Hallin, K. and Danielson, E. (2009) Being a Personal Preceptor for Nursing Students: Registered Nurses’ Experiences before and after Introduction of a Preceptor Model. Journal of Advanced Nursing, 65, 161-174. http://dx.doi.org/10.1111/j.1365-2648.2008.04855.x

[5] Flauveau, V., et al. (2008) Human Resources for Maternal for Maternal: Multipurpose or Specialists? Human Resources for Health, 6.

[6] Fleet, J., et al. (2008) Continuing Professional Development and Social Accountability: A Review of the Literature. BMA Inform Health, 22, 15-19.

[7] Galer, J., et al. (2005) Managers Who Led. A Handbook for Improving Health Services. Masachesets, Cambridge. 
[8] Gitonga, L. (2008) Positive Work Environment. Kenya Nursing Journal, 37, 13-15.

[9] Hallin, K. and Danielson, E. (2007) Registered Nurses Perception of Their Work and Professional Development. Journal of Advanced Nursing, 61, 62-70.

[10] Hennessy, et al. (2006) The Training and Development Needs of Midwives in Indonesia: Paper 1 of 3. Human Resources for Health, 4, 8. http://dx.doi.org/10.1186/1478-4491-4-8

[11] Hennessy, et al. (2006) The Training and Development Needs of Midwives in Indonesia: Paper 2 of 3. Human Resources for Health, 4, 9. http://dx.doi.org/10.1186/1478-4491-4-9

[12] Hennessy, et al. (2006) The Training and Development Needs of Midwives in Indonesia: Paper 3 of 3. Human Resources for Health, 4, 10. http://dx.doi.org/10.1186/1478-4491-4-10

[13] International Council of Nurses (ICN) (2007) Positive Work Environments. Geneva.

[14] Kaluzny, D. (2006) Health Care Management. Organization Design and Behavior. 5th Edition, Library of Congress, USA.

[15] Kenya Demographic Health Survey 2008-2009.

[16] Khomeiran, H. (2006) Practice Development and Health Care Governance; a Recipe for Modernization. Journal of Nursing Management, 12, 137-146.

[17] Kirwan, A. and Adams, J. (2008) Students' Views of Enquiry-Based Learning in a Continuing Professional Development Module. Nurse Education Today, 29, 448-455. http://dx.doi.org/10.1016/j.nedt.2008.09.003

[18] Legreid, A., et al. (2010) A Five-State CPD Pilot Program for Practising Pharmacists. The American Journal of Pharmaceutical Education, 74, 28. http://dx.doi.org/10.5688/aj740228

[19] Mbithe, A. (2005) Staff Development.

[20] Munro, M. (2008) Continuing Professional Development and the Charity Paradigm: Interrelated Individual, Collection and Organization Issues about Continuing Professional Development. Nursing Education Today, 28, 953-961. http://dx.doi.org/10.1016/j.nedt.2008.05.015

[21] Ministry of Health Kenya (2007) National Reproductive Health Policy. Enhancing Reproductive Health Status for all Kenyans.

[22] Ministry of Health Kenya (2007) Service Charters for Provision of Health Services to Patient and Clients in Kenya. 